\title{
Sensory Evaluation of Moringa- Probiotic Yogurt Containing Banana, Sweet Potato or Avocado
}

\author{
Megan Kuikman ${ }^{1} \&$ Colleen P. O'Connor ${ }^{1}$ \\ ${ }^{1}$ Division of Food and Nutritional Sciences, Brescia University College, London, Canada \\ Correspondence: Colleen P. O'Connor, Brescia University College, Western University, London, Ontario, N6G \\ 1H2, Canada. Tel: 1-519-432-8353 x28249. E-mail: colleen.oconnor@uwo.ca
}

Received: May 5, 2015 Accepted: August 25, 2015 Online Published: September 21, 2015

doi:10.5539/jfr.v4n5p165 URL: http://dx.doi.org/10.5539/jfr.v4n5p165

\begin{abstract}
This study evaluated the effects of adding selected fruits and vegetables local to Mwanza, Tanzania on the sensory qualities of probiotic yogurt supplemented with Moringa oleifera, a local tree with a high micronutrient and protein content. A total of five samples were evaluated: 1) Probiotic yogurt (control), 2) Moringa probiotic yogurt, 3) Moringa-banana probiotic yogurt, 4) Moringa-sweet potato probiotic yogurt, and 5) Moringaavocado probiotic yogurt. Consumers $(\mathrm{n}=37)$ rated the five different samples on a 9-point hedonic scale for four sensory characteristics (flavour, appearance, texture and overall quality). The control sample and the Moringa-banana sample had significantly higher ratings $(\mathrm{p}<0.05)$ than the Moringa sample for appearance, flavour, texture and overall quality. The Moringa-banana sample was not found to be significantly different than the control sample for all sensory characteristics $(\mathrm{p}>0.05)$. Overall, the addition of banana to Moringa probiotic yogurt resulted in a product with comparable sensory qualities to probiotic yogurt alone.
\end{abstract}

Keywords: Lactobacillus rhamnosus GR-1, Moringa oleifera, probiotic, consumer test, yogurt, Tanzania

\section{Introduction}

"Yogurt is the food produced by culturing one or more optional dairy ingredients .... with a characterizing bacterial culture that contains the lactic acid-producing bacteria, Lactobacillus bulgaricus and Streptococcus thermophilus" (Food and Drug Administrations [FDA], 2014). These lactic-acid bacteria convert lactose into lactic acid by first splitting lactose into glucose and galactose and then converting glucose into lactic acid, resulting in a decreased $\mathrm{pH}$ while the galactose tends to accumulate in the fermenting milk (Lourens-Hattingh \& Viljoen, 2001). Yogurt temperature is then reduced to stop bacterial growth (Clark, Costello, Drake, \& Bodyfelt, 2009). Many compounds are present in yogurt but acetylaldehyde is mainly responsible for the typical yogurt aroma (Hadman, Kunsman, \& Deanne, 1971).

Probiotics, which can be defined as "live microorganisms which when administered in adequate amounts confer a health benefit on the host" (Reid, 2010), grow well in milk, making yogurt an excellent carrier (Reid, 2010). The conventional yogurt starter cultures do not have the ability to survive passage through the human gastrointestinal tract (Gilliland, 1979), while probiotics do have the ability to alter the composition of the microbiota (Conly \& Johnston, 2004). Probiotic yogurt has been shown to be comparable to standard yogurt for appearance, flavour, texture and overall quality (Hekmat \& Reid, 2006).

Western Heads East (WHE) is Western University's community response to the HIV/AIDS crisis in Africa. Eastern and Southern Africa represent only 5\% of the world's population, yet half of the world's population living with the human immunodeficiency virus (HIV)/acquired immunodeficiency syndrome (AIDS) reside in these areas (UNICEF, 2013). Additionally, the HIV/AIDS epidemic is occurring in populations where malnutrition is endemic (World Health Organization [WHO], 2003). WHE began a probiotic micro-enterprise initiative in Eastern Africa by introducing community probiotic yogurt kitchens where local women make yogurt containing the probiotic strain Lactobacillus rhamnosus GR-1 and sell it in the community. Numerous health benefits for those living with HIV have been associated with the consumption of probiotics, including an increase in CD4 count (Irvine et al., 2010) and resolved diarrhea (Anukam, Osazuwa, Osadolor, Bruce, \& Reid, 2008). This venture not only supplies a healthy product to the community, but also empowers the women involved by providing an income source. 
Moringa oleifera is a drought-tolerant tree that is cultivated in East Africa and has an outstanding nutrient content (Moringanews network, 2007). On a gram per gram comparison, Moringa leaves contain at least twice the protein of milk, are richer in iron than beef and lentils, are richer in calcium than milk and are as rich in vitamin A as carrots (Moringanews network, 2007). Since externally fortifying the probiotic-yogurt with micronutrients is unsustainable due to the high costs of importation, fortifying the probiotic-yogurt with Moringa is a locally available and sustainable alternative (Van Tienen et al., 2011).

Table 1. Nutrient content of 17.09g of Moringa vs. Recommended Dietary Allowance (RDA)

\begin{tabular}{llll}
\hline Nutrient & $17.09 \mathrm{~g}$ Moringa & RDA & $\%$ RDA/17.09g of Moringa \\
\hline Proteins & $4956 \mathrm{mg}$ & $0.8 \mathrm{~g} / \mathrm{kg}$ body weight/day & N/A \\
Vitamin A & $2669 \mathrm{IU} \approx 133.5 \mu \mathrm{g}$ & $\begin{array}{l}\text { Males- } 900 \mu \mathrm{g} / \text { day } \\
\text { Females- } 700 \mu \mathrm{g} / \text { day }\end{array}$ & $\begin{array}{l}\text { Males- } 15 \% \\
\text { Females- } 19 \%\end{array}$ \\
Calcium & $329 \mathrm{mg}$ & $1000 \mathrm{mg} /$ day & $33 \%$ \\
Magnesium & $72 \mathrm{mg}$ & Males- $420 \mathrm{mg} /$ day & Males- $17 \%$ \\
& & Females- $320 \mathrm{mg} /$ day & Females- $23 \%$ \\
Phosphorus & $46 \mathrm{mg}$ & $700 \mathrm{mg} /$ day & $6.6 \%$ \\
Potassium & $237 \mathrm{mg}$ & $4700 \mathrm{mg} /$ day* & $5.0 \%$ \\
Copper & $0.17 \mathrm{mg}$ & $0.9 \mathrm{mg} /$ day & $19 \%$ \\
Iron & $4.8 \mathrm{mg}$ & Males- $8 \mathrm{mg} /$ day & Males- $60 \%$ \\
& & Females- $18 \mathrm{mg} /$ day & Females- $27 \%$ \\
Zinc & $0.43 \mathrm{mg}$ & Males- $11 \mathrm{mg} /$ day & Males- $3.9 \%$ \\
& & Females- $8 \mathrm{mg} /$ day & Females- $5.4 \%$ \\
Manganese & $1.43 \mathrm{mg}$ & Males- $2.3 \mathrm{mg} /$ day* & Males- $62 \%$ \\
& & Females- $1.8 \mathrm{mg} /$ day* & Females- $79 \%$ \\
\hline
\end{tabular}

*Adequate intake (AI) because no RDA available.

Moringa's addition to probiotic yogurt may have growth-enhancing effects on Lactobacillus rhamnosus GR-1 when the probiotic yogurt is stored at $4^{\circ} \mathrm{C}$ (Van Tienen et al., 2011). A similar study also found that Moringa may have growth enhancing properties on Lactobacillus rhamnosus GR-1 growth except perhaps at higher concentrations of Moringa (1\%) and when sugar is also present in the probiotic yogurt (Hekmat, Morgan, Soltani, \& Gough, 2015). The possible growth enhancing effects of Moringa are significant because in order to produce health benefits, bacterial colony formation cannot fall below $10^{6} \mathrm{CFU} / \mathrm{mL}$ (Kechagia et al., 2013) and (and). Hence Moringa could potentially enhance the shelf-life of the probiotic yogurt (Van Tienen et al., 2011). However, the sensory properties (appearance, flavour, texture and overall quality) of yogurt samples without Moringa were strongly preferred over samples with Moringa. No difference in sensory properties was seen when rating samples with different concentrations of Moringa (Van Tienen et al., 2011).

Past research in East Africa has tried to improve both consumer acceptability and nutrient density of the probiotic yogurt served by the yogurt kitchens. One study found that participants preferred yogurt products that were sweet, subtly flavoured, and maintained a smooth, creamy, homogenous texture (Irvine \& Hekmat, 2011). Irvine and Hekmat, 2011 tested 5 different samples of probiotic yogurt with added fruits and vegetables in Tanzania and found that a mashed sweet potato sample that also contained cooked onions and garlic received the best overall score and had the least inter-subject variation. Another sample containing banana, papaya and honey was also well received by participants. When $5 \%$ sugar was added to probiotic yogurt with low concentrations of Moringa (0.5\%) it was rated acceptable as a yogurt, but when a concentration of $1 \%$ Moringa was used with 5\% sugar it still had a strong, undesirable flavour (Hekmat et al., 2015). By adding local fruits and vegetables to Moringa-probiotic yogurt, it is hypothesized that the sensory properties may be improved. This has the potential to further improve the health of those receiving probiotic yogurt from the community kitchens in East Africa, especially those with HIV, because of the extra micronutrients provided by Moringa. The objective of this study was to evaluate the acceptability of local fruits and vegetables in Moringa- probiotic yogurt. 


\section{Materials and Methods}

\subsection{Probiotic Mother Culture Preparations}

The Lactobacillus rhamnosus GR-1 probiotic mother culture was prepared at the National Institute of Medical Research (NIMR) in Mwanza. The probiotic microorganisms were added to de Man, Rogosa and Sharp (MRS) broth and incubated anaerobically using BBL gas packs at $37^{\circ} \mathrm{C}$ overnight $(17-18$ hours). Milk (3.5\% fat) was sterilized the next day in an autoclave at $121^{\circ} \mathrm{C}$ and 15 psi for 15 minutes followed by the addition of $2 \%$ of the incubated MRS. This was then incubated anaerobically at $37^{\circ} \mathrm{C}$ for 18 hours.

\subsection{Probiotic Yogurt Productions}

Standardized milk ( $3.5 \%$ fat) was heated to $87^{\circ} \mathrm{C}$ and the temperature maintained for 30 minutes under constant stirring. The milk was cooled to $37^{\circ} \mathrm{C}$ and $2 \%$ yogurt and $4 \%$ probiotic mother culture were added to the pasteurized milk. Raw banana and avocado were washed, peeled, pureed and placed into the bottom of separate containers. The sweet potato was boiled and cooled prior to blending. Raw banana and avocado were used to prevent the loss of vitamins and minerals (Severi, Bedogni, Manzieri, Poli, \& Battistini, 1997) and to create a product that is easily replicable for the local women working in the yogurt kitchens. To prevent contamination, all fruits and vegetables were thoroughly washed and peeled before use. The pasteurized milk was poured over top of the pureed fruits and vegetables in the containers. A total of $250 \mathrm{ml}$ of fruit or vegetable were added per $1000 \mathrm{ml}$ of yogurt. These were kept at $37^{\circ} \mathrm{C}$ for 6 hours to allow for adequate fermentation and a $\mathrm{pH}$ comparable to similar studies (Clark et al., 2009). After this, the product was refrigerated at $4^{\circ} \mathrm{C}$ for 12 hours to allow cooling and to stop bacterial growth (Clark et al., 2009). Next, 17.09g of dried Moringa leaves per 1L of yogurt were stirred into the chilled yogurt and fruit/vegetables samples prior to serving. The Moringa was not heat treated or introduced into the pasteurized milk with the pureed fruits and vegetables because it interfered with yogurt thickening. This amount of Moringa was chosen based on previous research (Van Tienen et al., 2011) because one liter of yogurt containing Moringa corresponds to $19 \%$ of the RDA of vitamin A for women and $15 \%$ of the RDA of vitamin A for men, making it a "good source" of vitamin A (Government of Canada, 2012). Table 1 lists the nutrient content of 17.09g of Moringa (Van Tienen et al., 2011) and the RDA reported by Health Canada (2005).

\subsection{Consumer Test}

\subsubsection{Consumers}

The Western University Research Ethics Board approved the research protocol. All sensory testing took place in the district of Mabatini in Mwanza, Tanzania. Inclusion criteria for participation consisted of understanding the intent of the study, being over 18 years of age, and the ability to provide consent. Exclusion criteria included lactose intolerance and/or food allergies to milk, Moringa, banana, avocado, or sweet potato. Participants were recruited via posters hung in the community one week before the evaluation. On the day of the evaluation, posters were handed out as an additional recruitment effort. Eligible participants received a letter of information and signed a consent form prior to participation. All forms were in Swahili and the consumer test took place in Swahili through a translator. As compensation for participation, participants received a voucher for $500 \mathrm{ml}$ of probiotic yogurt.

\subsubsection{Sample Preparation}

Five samples were selected for the consumer test. The selected yogurt samples included the probiotic yogurt (control), Moringa probiotic yogurt, Moringa-banana probiotic yogurt, Moringa-sweet potato probiotic yogurt, and Moringa-avocado probiotic yogurt. The consumer test occurred the day after yogurt preparation. Samples were presented in standardized amounts in clear cups in a counterbalanced order. Enough of each sample was given to allow for re-tasting if desired. Each sample was designated a random three-digit code, which appeared on the corresponding cups.

\subsubsection{Consumer Test}

The consumer test took place in the quiet back room of the Mabatini community yogurt kitchen. Two consumer tests took place simultaneously. After reading the letter of information and providing informed consent, participants were given five samples of probiotic yogurt in a random counterbalanced order, an evaluation form, a pencil, a glass of water, and a plastic spoon for each sample. Participants were instructed not to communicate with each other and to rinse their mouth between samples with water. Instructions were given through a translator in Swahili. The same instructions were listed at the top of each evaluation form in Swahili. Participants assessed each sample on a scale of 1 (dislike extremely) to 9 (like extremely) for appearance, taste, texture and overall quality. Further questions were asked to explain their evaluations. 


\subsection{Statistical Analysis:}

The mean and standard deviation were used to summarize the ratings for each sensory characteristic (texture, flavour, appearance, and overall quality) for all yogurt samples. Repeated measures analysis of variance (ANOVA) was used to compare the within-group mean change for each category. Tukey's Honestly Significant Difference (HSD) was then used to determine how the means of each yogurt sample compared to each other. A p-value $<0.05$ was considered statistically significant.

\section{Results}

\subsection{Consumer Test}

\subsubsection{Demographics and Product Usage Questionnaire}

A total of 40 participants took part in the evaluation but the data of 3 participants were excluded from analysis due to incomplete consumer test forms. Of the 37 participants who completed the study, the majority were male $(75 \%)$ and consumed yogurt on a daily basis $(77 \%)$. A vast majority of participants were male due to the nature of the local culture. Most females tend to be at home during the day while males work outside the home within the community. All participants had previously consumed yogurt. The basic demographic information of participants is listed in Table 2.

Based on the 9-point hedonic scale, the results of the mean ratings for appearance, taste, texture and overall quality can be found in table 3 . Significant differences $(p<0.05)$ between mean sensory scores were found for appearance, flavour, texture and overall quality. The control sample had the highest score for appearance, flavour, texture and overall quality, while the Moringa sample had the lowest score for all four categories. The Moringabanana sample contained significantly higher scores in all sensory categories except texture than all other samples except for the control.

\subsubsection{Appearance}

While the control sample was white in colour and had a thick consistency, the four remaining samples had a soft-green colour but held a similar consistency. The mean scores for appearance ranged from dislike slightly (Moringa) to like moderately (control). The Moringa-banana sample (6.9 \pm 2.0$)$ and the control sample (7.1 \pm 1.8$)$ had significantly higher ratings $(\mathrm{p}<0.05)$ for appearance than the Moringa sample $(4.6 \pm 2.8)$, Moringa-sweet potato sample (5.4 \pm 2.2$)$ and Moringa-avocado sample (5.5 \pm 2.6$)$. However, there was no significant difference ( $\mathrm{p}=0.991$ ) between the control and Moringa-banana sample.

\subsubsection{Flavour}

The mean scores for flavour ranged from neither like nor dislike (Moringa-avocado) to like moderately (control). The Moringa-banana sample (6.7 \pm 2.1$)$ and the control sample $(6.9 \pm 2.1)$ had significantly higher ratings $(\mathrm{p}<0.05)$ for flavour than the Moringa sample (5.4 \pm 2.3 ) and Moringa-avocado sample (5.1 \pm 2.4$)$. No significant difference ( $\mathrm{p}>0.05$ ) existed between the control, Moringa-banana sample and the Moringa- sweet potato (5.7 \pm 2.5$)$ sample.

\subsubsection{Texture}

The mean scores for texture ranged from neither like nor dislike (Moringa) to like moderately (control). The Moringa-banana sample $(6.2 \pm 2.4)$ and the control sample $(6.7 \pm 2.0)$ had significantly higher ratings $(\mathrm{p}<0.05)$ for texture than the Moringa sample (4.8 \pm 2.4$)$. No significant difference $(\mathrm{p}>0.05)$ existed between the control, Moringa-banana sample, Moringa- sweet potato sample (5.6 \pm 2.1$)$ and the Moringa-avocado sample (5.3 \pm 2.4 ).

\subsubsection{Overall Quality}

The mean scores for overall quality ranged from neither like nor dislike (Moringa) to like moderately (control). The overall quality score for the control sample (7.2 \pm 2.3$)$ and Moring-banana sample (6.2 \pm 2.5$)$ were significantly higher $(\mathrm{p}<0.05)$ than the Moringa sample $(4.5 \pm 2.6)$. The control sample was also significantly higher than the Moringa- sweet potato sample (5.2 \pm 2.7 ) and Moringa-avocado sample (5.4 \pm 2.6$)$. No significant difference $(\mathrm{p}=0.383)$ existed between the control and Moringa-banana sample. 
Table 2. Sex, age and product-usage of participants $(\mathrm{n}=37)$

\begin{tabular}{lll}
\hline Participant characteristics & & \\
\hline Sex & Male & $76 \%$ \\
\multirow{3}{*}{ Age } & Female & $24 \%$ \\
\cline { 2 - 3 } & $18-24$ years & $43 \%$ \\
& $25-50$ years & $41 \%$ \\
Product-usage & $>50$ years & $16 \%$ \\
\cline { 2 - 3 } & $1 /$ day & $84 \%$ \\
& $1 /$ week & $5 \%$ \\
& $1 /$ month & $8 \%$ \\
& Never & $0 \%$ \\
\hline
\end{tabular}

Table 3. Panelists $(n=37)$ mean sensory score (standard deviation) for appearance, flavour, texture and overall quality on a 9-point hedonic scale for each sample

\begin{tabular}{lllll}
\hline Sample & Appearance & Flavour & Texture & Overall Quality \\
\hline Moringa & $4.6 \pm 2.8^{\mathrm{b}}$ & $5.4 \pm 2.3^{\mathrm{b}}$ & $4.8 \pm 2.4^{\mathrm{b}}$ & $4.5 \pm 2.6^{\mathrm{b}, \mathrm{c}}$ \\
Moringa- banana & $6.9 \pm 2.0^{\mathrm{a}}$ & $6.7 \pm 2.1^{\mathrm{a}}$ & $6.2 \pm 2.4^{\mathrm{a}}$ & $6.2 \pm 2.5^{\mathrm{a}, \mathrm{c}}$ \\
Moringa -sweet potato & $5.4 \pm 2.2^{\mathrm{b}}$ & $5.7 \pm 2.5^{\mathrm{a}, \mathrm{b}}$ & $5.6 \pm 2.1^{\mathrm{a}, \mathrm{b}}$ & $5.2 \pm 2.7^{\mathrm{c}}$ \\
Moringa- avocado & $5.5 \pm 2.6^{\mathrm{b}}$ & $5.1 \pm 2.4^{\mathrm{b}}$ & $5.3 \pm 2.4^{\mathrm{a}, \mathrm{b}}$ & $5.4 \pm 2.6^{\mathrm{c}}$ \\
Control & $7.1 \pm 1.8^{\mathrm{a}}$ & $6.9 \pm 2.1^{\mathrm{a}}$ & $6.7 \pm 2.0^{\mathrm{a}}$ & $7.2 \pm 2.3^{\mathrm{a}}$ \\
\hline
\end{tabular}

Note. Where $1=$ dislike extremely, $2=$ dislike very much, $3=$ dislike moderately, $4=$ dislike slightly, $5=$ neither like or dislike, $6=$ like slightly, $7=$ like moderately, $8=$ like very much, and $0=$ like extremely; $p<0.05$ for appearance, flavour and overall quality. For each characteristic, treatments with the same letter are not statistically different by a Tukey's Test at the significance level of $\mathrm{P}<0.05$.

\section{Discussion}

The objective of this study was to observe the effects of adding fruits and vegetables on the sensory qualities of probiotic yogurt supplemented with Moringa. We hypothesized that the addition of fruits and vegetables would improve the sensory qualities, resulting in a more acceptable product. Like previous studies, Moringa-probiotic yogurt was liked significantly less than the control sample for appearance, taste, texture and overall quality. This study showed that by adding banana to Moringa-probiotic yogurt it can be made comparable to probiotic yogurt alone. Moringa-banana probiotic yogurt had the second highest mean score in all categories and had significantly higher ratings than the Moringa-probiotic yogurt for appearance, taste, texture and overall quality. Furthermore, no significant difference existed between it and the control sample, indicating that the two samples are comparable. Likewise, we found no difference between the control sample and the Moringa-sweet potato sample for flavour and texture, and the Moringa-avocado sample for texture, suggesting that they are also comparable.

The findings of this study are important because they show that Moringa-probiotic yogurt could become an acceptable alternative to probiotic yogurt in East African communities when supplemented with banana. Moringa-probiotic yogurt is nutritionally superior to probiotic yogurt alone due to its high nutrient content (Moringanews network, 2007). Those living with HIV/AIDS would especially benefit because the increased nutritional needs caused by the HIV virus (Mangili, Murman, Zampini, Wanke, \& Mayer, 2006; Kosmiski, 2011) would be better met by this novel yogurt when compared with probiotic yogurt alone. Furthermore, all samples tested incorporated only simple, locally available and cost-effective foods, enabling the local communities through the yogurt kitchen micro-enterprises to easily replicate the samples with little additional costs involved. Moringa grows readily in East Africa so these facilities could grow their own Moringa to incorporate into the probiotic yogurt. These samples could therefore be produced and sold in the yogurt kitchens.

A limitation of this study is that the majority of participants were men $(75 \%)$ and were recruited from only one region in Mwanza. Because food preferences are partially determined by cultural forces, it was important that the 
consumer test be conducted in the region where the product would be sold (Robalino \& Robson, 2013).

\section{Conclusion}

Our study showed that by adding banana, sweet potato or avocado to Moringa-probiotic yogurt, it can be made comparable to probiotic yogurt alone. This product may offer additional health benefits over probiotic yogurt alone due to the added nutrients. Future studies should investigate the impact of Moringa-probiotic yogurt consumption on the health of consumers, especially those living with HIV. Studies should also look at further improving the sensory qualities of Moringa-probiotic yogurt in order to make it superior to probiotic yogurt alone and should include a sample with a proportional amount of female and male participants.

\section{Acknowledgments}

The authors would like to thank the National Institute of Medical Research for helping to culture the probiotic microorganisms and for providing support; the Tukwamuane's Women's Group for the use of their facilities for data collection; Western Heads East for support and encouragement; and Brescia University College for providing funding for this project.

\section{References}

Anukam, K. C., Osazuwa, E. O., Osadolor, H. B., Bruce, A. W., \& Reid, G. (2008). Yogurt containing probiotic Lactobacillus rhamnosus GR-1 and L. reuteri RC-14 helps resolve moderate diarrhea and increase CD4 Count in HIV/AIDS patients. Journal of Clinical Gastroenterology, 42(3), 239-243. http://dx.doi.org/10.1097/MCG.0b013e31802c7465

Clark, S., Costello, M., Drake, M., \& Bodyfelt, F. (2009). The consumer test of dairy products (2nd ed.). http://dx.doi.org/ 10.1007/978-0-387-77408-4

Conly, J. M., \& Johnston, L. B. (2004). Coming full circle: From antibiotics to probiotics and prebiotics. Canadian Journal of Infectious Diseases, 15(3), 161-163.

Food and Drug Administrations [FDA]. (2014). CFR-code of federal regulations title 21. Retrieved from http://www.accessdata.fda.gov/scripts/cdrh/cfdocs/cfcfr/CFRSearch.cfm?fr=131.200

Gilliland, S. E. (1979). Beneficial inter-relationships between certain microorganisms and humans: Candidate microorganisms for use as dietary adjuncts. Journal of Food Protection, 42(2), 164-167.

Government of Canada. (2012). Nutrient content claims: What they mean. Retrieved from http://healthycanadians.gc.ca/eating-nutrition/label-etiquetage/nutrient_claims-allegations_nutriment-eng.ph $\mathrm{p}$

Hadman, I. Y., Kunsman, J. E., \& Deanne, D. D. (1971). Acetaldehyde production by combined yogurt cultures. Journal of Dairy Science, 54(7), 1080-1082. http://dx.doi.org/ 10.3168/jds.S0022-0302(71)85975-1

Health Canada. (2005). Dietary reference intakes. Retrieved from http://www.hc-sc.gc.ca/fnan/nutrition/reference/index-eng.php

Hekmat, S., Morgan, K., Soltani, M., \& Gough, R. (2015). Consumer test of locally-grown fruit purees and inulin fibre on probiotic yogurt in Mwanza, Tanzania and the microbial analysis of probiotic yogurt fortified with Moringa oleifera. Journal of Health, Population and Nutrition, 33(1), 60-68.

Hekmat, S., \& Reid, G. (2006). Sensory properties of probiotic yogurt is comparable to standard yogurt. Nutrition Research, 26(4), 163-166. http://dx.doi.org/10.1016/j.nutres.2006.04.004

Irvine, S. L., \& Hekmat, S. (2011). Evaluation of sensory properties of probiotic yogurt containing food products with prebiotic fibres in Mwanza, Tanzania. Food and Nutrition Sciences, 2, 434-439. http://dx.doi.org/10.4236/fns.2011.25061

Irvine, S. L., Hummelen, R., Hekmat, S., Looman, C. W., Habbema, J. D., \& Reid, G. (2010). Probiotic yogurt consumption is associated with an increase of CD4 count among people living with HIV/AIDS. Journal of Clinical Gastroenterology, 44(9), 201-205. http://dx.doi.org/10.1097/MCG.0b013e3181d8fba8

Kosmiski, L. (2011). Energy expenditure in HIV infection. American Journal of Clinical Nutrition, 94(6), 16775-16825. http://dx.doi.org/10.3945/ ajcn.111.012625

Kechagia, M., Basoulis, D., Konstantopoulou, S., Dimitriadi, D., Gyftopoulou, K., Skarmoutsou, N., \& Fakiri, E. M. (2013). Health benefits of probiotics: A review. International Scholarly Research Notices, 2013, 1-7. http://dx.doi.org/10.5402/2013/481651

Lourens-Hattingh, A., \& Viljoen, B. C. (2001). Yogurt as probiotic carrier. International Dairy Journal, 11(1), 
1-17. http://dx.doi.org/10.1016/S0958-6946(01)00036-X

Mangili, A., Murman, D. H., Zampini, A. M., Wanke, C. A., \& Mayer, K. H. (2006). Nutrition and HIV infection: Review of weight loss and wasting in the era of highly active antiretroviral therapy from the nutrition for healthy living cohort. Clinical Infectious Disease, 42(6), 836-842. http://dx.doi.org/10.1086/500398

Moringanews network. (2007). The nutritional value of Moringa oleifera Lam leaves: What can we learn from figures? Retrieved from http://www.moringanews.org/doc/GB/Posters/Broin_poster.pdf

Reid, G. (2010). The potential role for probiotic yogurt for people living with HIV/AIDS. Gut Microbes, 1(6), 411-414. http://dx.doi.org/10.4161/gmic.1.6.14079

Robalino, N., \& Robson, R. J. (2013). Genes, culture, and preferences. Biological Theory, 8(2), 151-157. http://dx.doi.org/ 10.1007/s13752-013-0108-0

Severi, S., Bedogni, G., Manzieri, A. M., Poli, M., \& Battistini, N. (1997). Effects of cooking and storage methods on the micronutrient content of foods. European Journal of Cancer Prevention, 6(1), 21-24. http://dx.doi.org/ 10.1097/00008469-199703001-00005

UNICEF. (2013). Eastern and Southern Africa: HIV and AIDS. Retrieved from http://www.unicef.org/esaro/5482_HIV_AIDS.html

Van Tienen, A., Hullegie, Y. M., Hummelen, R., Hemsworth, J., Changalucha, J., \& Reid, G. (2011). Development of a locally sustainable functional food for people living with HIV in Sub-Saharan Africa: Laboratory testing and consumer test. Beneficial Microbes, 2(3), 193-198. http://dx.doi.org/10.3920/BM2011.0024

World Health Organization. (2003). Nutrient requirements for people living with HIV/AIDS. Switzerland, Geneva: World Health Organization.

\section{Copyrights}

Copyright for this article is retained by the author(s), with first publication rights granted to the journal.

This is an open-access article distributed under the terms and conditions of the Creative Commons Attribution license (http://creativecommons.org/licenses/by/3.0/). 